\title{
Evolutionary and differential psychology: conceptual conflicts and the path to integration
}

\section{Tim Marsh * and Simon Boag}

Department of Psychology, Macquarie University, Sydney, NSW, Australia

\section{Edited by:}

Karol Osipowicz, Jefferson

Neuroscience Hospital, USA

Reviewed by:

Lei Chang, Chinese University of

Hong Kong, Hong Kong

Andreas Wilke, Clarkson University,

USA

\section{${ }^{*}$ Correspondence:}

Tim Marsh, Department of

Psychology, Macquarie University,

Balaclava Rd., North Ryde, Sydney,

NSW 2109, Australia

e-mail: timothy.marsh@mq.edu.au
Evolutionary psychology has seen the majority of its success exploring adaptive features of the mind believed to be ubiquitous across our species. This has given rise to the belief that the adaptationist approach has little to offer the field of differential psychology, which concerns itself exclusively with the ways in which individuals systematically differ. By framing the historical origins of both disciplines, and exploring the means through which they each address the unique challenges of psychological description and explanation, the present article identifies the conceptual and theoretical problems that have kept differential psychology isolated not only from evolutionary psychology, but from explanatory approaches in general. Paying special attention to these conceptual problems, the authors review how these difficulties are being overcome by contemporary evolutionary research, and offer instructive suggestions concerning how differential researchers (and others) can best build upon these innovations.

Keywords: bottom-up explanation, differential psychology, evolutionary psychology, individual differences, integration, top-down explanation, unification of psychology
Psychology has been described as a science impaired by disunity (Gladin, 1961; Meehl, 1978; Kantor, 1979; Staats, 1983, 1999; de Groot, 1990; Yanchar and Slife, 1997; Henriques, 2003, 2004, 2011; Goertzen, 2008, 2010; Mandler, 2011). There is, however, disagreement over precisely how large a problem theoretical and institutional disunity is for psychologists and behavioral scientists in general (Dixon, 1983; Baars, 1984, 1985; Matarazzo, 1987, 1992; Bower, 1993; Neisser, 1995; Kelly, 1998; Kassinove, 2002; Stam, 2004). Nevertheless, integration is widely considered a desirable course of action, if only for the potential benefits of combining disparate theories and findings within a common conceptual space (Staats, 1999; Henriques, 2003, 2011; Goertzen, 2008). In recent years, the adaptationist approach of evolutionary psychology has emerged as strong candidate for central inclusion in a unifying meta-theory of psychology (Penke et al., 2007a,b; Tooby and Cosmides, 2007; Webster, 2007; Daly and Wilson, 2008; Buss, 2009). Stated briefly, adaptationism is a paradigm for analyzing the physical and behavioral characteristics of organisms by focusing on functionally complex features which can only arise through natural selective pressures (see Daly and Wilson, 1999 for a brief review of the origins of adaptationism in behavioral science). Despite some enduring camps of resistance (Rose and Rose, 2000; Buller, 2005; Richardson, 2007), the literature shows a trend of increasing acceptance of adaptationism in diverse fields of psychology (Confer et al., 2010; Fitzgerald and Whitaker, 2010). Many recent unification efforts orient around evolutionary theories and approaches (Sternberg and Grigorenko, 2001; Henriques, 2003, 2004, 2008, 2011; Gintis, 2007). Nevertheless, although the adaptationist approach can and has been readily applied to an extensive range of psychological phenomena, as highlighted in Confer et al. (2010) some areas of psychology pose unique theoretical and methodological difficulties, which evolutionists must (befittingly) adapt to. Perhaps the largest category of phenomena that demands a revision of traditional adaptationist analyses is the systematic occurrence of variation in normative psychological characteristics, the domain of personality and individual differences (Buss, 2009; Buss and Hawley, 2011). As Confer et al. (2010) summaries: "Evolutionary psychology has been far more successful in predicting and explaining species-typical and sex-differentiated psychological adaptations than explaining variation within species or within the sexes" (p. 123). The recent innovations on this front discussed later in this article are best appreciated relative to the history and present state of traditional differential psychology.

Over the past century, the study of normative individual differences in thought, behavior and ability (hereafter referred to by the umbrella term "differential psychology") has become one of the largest and most popular arms of psychological science (Lubinski, 2000; Borghans et al., 2011). Differential psychology has intimate ties to multiple fields of applied psychology, including psychometric assessment, developmental and educational psychology, lifestyle and vocational adjustment, and our shifting conceptions of psychopathology (Lubinski, 2000). Despite this, differential psychology has a long history of remaining largely theoretically autonomous from related sub-disciplines of psychology. To this day, there is little cross-pollination between even the largest areas of differential psychology and their immediately adjacent research fields (Mischel, 1968, 1973; Cervone, 1991; Borsboom, 2005; Cramer et al., 2010). To illustrate the point, the differential psychology domain of cognitive ability/intelligence testing has developed largely independent of the insights of functional cognitive psychology (Cronbach, 1957; Neisser et al., 1996; 
Garlick, 2002, 2003; Anderson, 2005). Additionally, differential trait theories have become a prevailing approach in the study of personality, whilst remaining predominantly separate from other leading conceptions and models within personality psychology (see Block, 1989, contrasted with 2010, for examples both before and after the rise of the Five Factor Approach). Evolutionary psychology represents only the most recent theoretical approach that must now struggle to integrate with the relatively independent niche carved out by the traditions of differential psychology.

While both evolutionary psychology and differential psychology are immensely diverse and heterogeneous fields, the arguments of this paper seek to cast as wide and as relevant a net as possible. As such, primary focus shall be given to fundamental conceptual and methodological elements that are nearubiquitous characteristics of the respective fields, with more specific examples drawn from the most relevant and representative research areas available. By utilizing some often overlooked distinctions from the wider philosophy of science, examining the fundamental scientific tasks of description and explanation (and beyond this, forms of explanation), the authors seek to explore the apparent theoretical isolation of differential psychology, and argue that integration is possible only when descriptive efforts are designed to inform causal explanations. In approaching this contentious topic from a neglected theoretical perspective, this paper contributes a new argument to the collective evolutionarydifferential integration efforts started by David Buss almost 30 years ago (1984), an argument designed to address the fundamental conceptual concerns echoed by some critics of evolutionary psychology (Buller, 2005; Richardson, 2007). The current state of integration efforts and possible future avenues for individual differences research will also be discussed.

\section{A COMMON ANCESTOR}

During the formative period of the late 1800s, the precursors of both evolutionary and differential psychology were initially proposed as means to a common end. Methodologies emphasizing species-typical features and those emphasizing between-subjects variation share a number of common ancestors, perhaps the most illustrative of which is the career of Sir Francis Galton (Galton, 1889; Allen, 2002). Whereas vaguely evolutionarily-guided biological insights have shaped such influential theories as those of Sigmund Freud (Young, 2006) and B. F. Skinner (Skinner, 1966, 1984), Galton (a half-cousin to Charles Darwin) focused very specifically on the application of several Darwinian principles to studying the human species (Forest, 1995).

Galton is of central relevance to the history of personality and individual differences (Bynum, 2002), having pioneered the psychometric assessment of both abilities and dispositions, first articulating the paradigm of "nature vs. nurture," and developing statistical methods oriented around correlation and the use of regression toward the mean with standard deviations (Simonton, 2003). Though now remembered poorly for his advocacy of eugenics, Galton's endeavors in measuring variability and supplementing selective pressures in human populations were two necessary components of a single ambition: to preserve and aid the evolution of the human species, with particular regard towards human intelligence and character (Jensen, 2002; Seligman, 2002).
Galton understood that the most crucial aspects of Darwin's theory of evolution by natural selection can be broken down into two discrete concepts. Firstly, that all populations of organisms contain some meaningfully heritable variation, and second, that the differential efficacy of these variants with regard to the demands of survival and reproduction produce a form of selection (Darwin, 1859, 1871). The representative properties of any species will reliably change over time, in such a manner as to increase their contextual reproductive success, so long as sufficient variation and selection can occur. In the introductory pages of their recent edited book, Buss and Hawley (2011) state flatly: "Individual differences are indispensible for natural selection. Without heritable variants, natural selection-the only known process capable of creating and maintaining functional adaptations_could not occur." (p. ix).

From this perspective, we can appreciate, in much the same manner as Galton and his contemporaries, that the study of population variation and the study of selective pressures are two sides to the same coin. Both aspects are necessary to understand the history and present-state of biological and psychological functioning, and our richest insights must be born of complex interactions between the two. Thus, to understand the apparent rift that has since formed between these two philosophically congruent fields, one must turn an eye to their separate trajectories of historical implementation.

\section{CONTRASTING FOCUSES AND CONFLICTING METHODS}

The technological progression of the past 150 years has precluded the study of human variation and the study of human evolutionary design from developing hand-in-hand. Darwin's original articulation of evolutionary theory was inhibited from its inception by a lack of insight into the molecular mechanisms of heredity. While basic inheritance of biological traits had been well-observed, it was not until more than 50 years later, when Mendel's theories of genetics and Morgan's chromosome theory were integrated, that biologists were in a position to undertake meaningful investigations into the propagation of varying traits throughout a population (Huxley, 1942; Dennett, 1995a; Bowler, 2003; Olsson et al., 2006). From the beginning of the 20th century, the study of selective pressures was impaired for many decades, awaiting both the gradual stockpiling of heritability data, and the development of molecular-genetic and computer-modeling techniques.

During this time, several disciplines focusing on measuring and predicting population variation thrived (Stern, 1911), most notably the burgeoning field of differential psychology (Lamiell, 2003; Bergman and Trost, 2006; Uher, 2008). These early endeavors did not suffer at all in the absence of a study of selection, for the findings themselves were considered simply a cross-section of a presumably changing population. Since selection can only occur between generations, only measures of variation spanning over two or more generations would require insights into selection to be understood. It is during this period, while selection-focused sciences were still handicapped by technology that differential psychology flourished.

The early differential techniques fed strongly into many of the experimental psychology approaches of the era (Tucker et al., 
2005), enduring the dominance of behaviorism to then be reinvigorated by the cognitive revolution that followed (Block, 1989; Baum, 1994; Mandler, 2002; Miller, 2003). During this time, differential psychologists distanced themselves from the rapidly shifting theories in related fields, and came to rely heavily on their robust statistical constructs and improving ability to predict outcomes (Lubinski, 2000; Maltby et al., 2007). Growing beyond initial interests in improving the process of military recruitment, differential psychology forged close relationships with many areas of applied psychology (Tyler, 1965). The domains of personalityand intelligence-testing in particular, grew ever-more prominent in predicting and informing outcomes including educational development, vocational selection, risk-management, and mental and physical health outcomes, to name only a few (Karasek, 1979; Lubinski, 2000; Marks et al., 2005; Reisner, 2005; Maltby et al., 2007).

From the late 1980 s to the present day, differential psychology has fortified its position as a central pillar of psychological science, with influential constructs such as the "g" factor of intelligence and trait models of personality standing at the center of decades of empirical support (Chamorro-Premuzic and Furhnam, 2006; Reeve and Charles, 2008; Block, 2010). Contemporary personality and individual differences research is defined by constructs that rely little on grounding theories, but rather, are built on robust statistical data drawn from large populations (Borsboom, 2005). One might thus presume that researchers would regard differential psychology constructs as having limited or strictly instrumental use, relative to the explanatory theories they diverge from. To the contrary, however, trends in the literature suggest that differential constructs are thriving, while theory-based and qualitative research approaches are systematically disfavored (Rogers, 2000). One explanation for this bias is the "quantitative imperative" (Michell, 1990, 2003a,b): "The quantitative imperative is the view that in science, when you cannot measure, you do not really know what you're talking about, but when you can, you do" (Michell, 2003a p.5). According to Michell (2005) this quantitative imperative acts both as an explicit principle and as a subtle network of social and institutional biases. Through such influences, the individual differences field has come to embrace its historical overspecialization in nomothetic statistics as evidence of true scientific validity (Borsboom et al., 2004; Borsboom, 2005).

In contrast, early attempts to address human psychological phenomena with reference to selective pressures only began to emerge in the latter half of the $20^{\text {th }}$ century, under the umbrella-term "sociobiology" (Hamilton, 1954; Wilson, 1975). These attempts ultimately proved conceptually inadequate, as many were highly reminiscent of the genetic-determinist theories then-prevalent in ethology and zoology, or depended intimately on the then-controversial prospect of group-selection (Gould and Lewontin, 1979; Gould, 1981; Vining, 1986). Only in the late 1980s did the adaptationist paradigm of evolutionary psychology fully emerge (Buss, 1984, 1995; Cosmides and Tooby, 1989; Tooby and Cosmides, 1989), requiring another decade of development before the approach became widely acknowledged (Confer et al., 2010; Fitzgerald and Whitaker, 2010). Evolutionary psychologists established a refined adaptationist approach, drawing from contemporary cognitive psychology to strongly emphasize the modularity and domain-specificity of hypothesized psychological adaptations (Cosmides and Tooby, 1987, 1997; Nesse and Lloyd, 1992; Pinker and Bloom, 1992; Pinker, 1997). Evolutionary psychology specifically targeted those features of psychological functioning which are species-typical mechanisms that evolved in response to the recurring survival and reproductive challenges of Pleistocene epoch human ancestors (Buss, 1999, 2005). Such species-typical features offer an important means of empirical hypothesis-testing, as only ubiquitous, biologically-based features are likely to exist in similar forms cross-culturally (Buss et al., 1990; Barkow et al., 1992; Tooby and Cosmides, 1992; Buss, 2005).

As of the beginning of the 21st century, an apt summary of the two fields was that evolutionary psychology focuses on the features which are shared across our species, while differential psychology focuses on the ways in which the members of our species systematically differ (Borghans et al., 2011). Given their shared origins, one might presume that findings of the two approaches must be intrinsically disposed to integration. However, despite some attempts dating back to the formative years of evolutionary psychology (Buss, 1984, 1991), integration efforts have faced theoretical and practical difficulties, to a degree that some view as an interdisciplinary hostility (Anderson, 2005; Muncer, 2011).

To understand this divide, it is necessary to explore some of the unique conceptual challenges that afflict psychology research more so than almost any other field of science. These conceptual difficulties lend disproportionate weight to variations in approach and methods, and are a driving force behind the characteristic rifts between the sub-disciplines of psychology (see Goertzen, 2008 for a diverse account). Moreover, an exploration of these issues can offer an insight into the asymmetrical unification attempts between evolutionary and differential psychology especially (Pinker, 2002; Tooby et al., 2005; Rodeheffer et al., 2011), and provide specific means through which such conflicts may, and must, be overcome.

\section{THE UNIQUE CHALLENGES OF PSYCHOLOGICAL INQUIRY}

In order to discuss the challenges that psychology faces as a science, it is necessary to first clarify precisely what is meant by "science." While views on what constitutes "science" vary (Salmon, 1989; Gaukroger, 2006), the scientific enterprise generally consists of two major elements: the systematic observation and description of a particular set of natural phenomena, and the theory-guided explanation of the causes of said phenomena (Wilson, 1998; Cervone, 1999; Boag, 2011). In employing this definition, the authors seek to approximate the position advocated by Wilson (1998), and emphasize that the role of science is to "factor out human values" through procedural error-checking, with the goal of developing "representations of reality that are as accurate as possible."

\section{A SCIENCE WITHIN A BLACK BOX}

To understand the conceptual difficulties of psychological inquiry, it is illustrative to regard all aspects that cannot be immediately observed as existing within a figurative "black box." In the engineering sciences, a "black box" is the catch-all term for any 
system that has traceable outputs, and at least somewhat traceable inputs, but of which one can gain little to no direct insight into the internal processes that bridge between them (House, 1991; Nairne, 1997; Astbury and Leeuw, 2010). The black box nature of psychological phenomena poses few difficulties for the tasks of observation and description, as these are generally concerned with the system's inputs and outputs (behaviors, levels of activity, etc.). Black boxes do, however, pose substantial challenges to the task of explanation.

Since a phenomenon can only be explained via reference to those related antecedents which, in the past, caused its current state, black box systems concern observable phenomena (the outputs and inputs of the black box) which have causal relations to elements and/or objects that cannot be observed (Kitcher, 1985; Salmon, 1989; Cervone, 1999; Ketelaar and Ellis, 2000; Hüttemann and Love, 2011). Any explanatory account of the inputs or outputs of a black box must by necessity contain some incomplete space, permitting nothing more concrete than speculation. As an example, consider an alarm clock, with the standard inputs (an electric power cord) and outputs (patterns of light and sound). While one might reasonably presume that the device contains electrical circuits that keep time, we must acknowledge that without opening the box, one can only speculate as to precisely what form these internal components take. Relying only on the inputs and outputs, we have no means with which to distinguish between multiple options that achieve the same overt patterns, for any mechanism capable of keeping time, regardless of method, would be functionally identical.

This limitation underpins one of the defining characteristics of the scientific method: hypothesis-testing, which acts as an algorithmic process comprised of both the generative and selective phases that most diagnostic procedures rely on (Fisher, 1925; Kaplan, 1964). It is common when investigating natural phenomena to only have a subset amenable to direct measurement. As such, hypothesis-testing is employed to interpret predictive patterns in that which is observed, to infer the possible characteristics of the variables that cannot be observed (Bunge, 1963; Beizer, 1995). The black box metaphor need not only refer to physical limitations, but rather, a situation can present as a "black box" relative to the means of the investigator. Any situation is figuratively a black box, if vital explanatory details are amenable only to the hypothesis-testing of peripheral phenomena.

From a methodological perspective, the fundamental limit to the utility of hypothesis-testing is that a theory could only be definitively "proven" via the exhaustive disproving of all possible alternative hypotheses. For most kinds of black box situations, there are an effectively infinite number of alternative hypotheses concerning the character of the hidden sections. Thus, heuristics that guide investigators toward testing the most likely or plausible hypotheses are the saving grace that renders actual hypothesis-testing possible. Such heuristics are generally drawn from theory, however, and the more extensive or multi-layered the black box is, the more potentially inscrutable the input-output contingencies become (Fisher, 1925; Bunge, 1963; Kaplan, 1964; Beizer, 1995; Kaplan and Craver, 2011; also see Cervone, 1999 for psychology-specific discussion).
This fundamental challenge of constructing explanatory theories for complex black box phenomena is the central philosophical and conceptual difficulty that defines psychology as a science. To a degree largely unshared by any other natural science, the black box phenomena comprising the information-processing systems of humans and other animals are near-insurmountably complex. The subject matter of psychology concerns highly interpretable stimuli, passing through immensely long, largely immeasurable, variable and internally-referential causal sequences (Jaszczolt, 1996), to emerge as behavioral outputs that are themselves highly interpretable (De Los Reyes and Kazdin, 2008).

As an immediate consequence of this, sub-disciplines of psychology are particularly vulnerable to sectarianism and disunity. Most fields of psychology have, understandably, built their theories and explanatory models using those insights most conducive to answering their specific research questions (Matarazzo, 1992; Kelly, 1998). As a result many fields of psychology make dissonant or contradictory pragmatic assumptions about those aspects of the mental black box that they are not presently addressing. The mutually incompatible assumptions that characterize different research approaches appear to be responsible for the majority of institutional disunity in psychology, including the rift between evolutionary and differential psychology.

\section{REFINING EXPLANATORY THEORIES}

Although description is fundamentally necessary for explanation to occur, explanation is arguably the highest goal of science (Wilson, 1998; Cervone, 1999, 2005). As such, a research approach in psychology is perhaps the best judged in terms of its ability to constrain theories and predictions, so as to reliably draw maximum utility out of practical hypothesis-testing (see Kaplan, 1964, chapter 2 for general elaboration; for discussion specific to evolutionary psychology, see Resnik, 1996; Sober, 2000; Lewens, 2002).

There are, in general, three means of informing an explanatory theory prior to (or in conjunction with) prediction-testing of input-output contingencies (Bunge, 1963). The first, and often most difficult, option is to attempt to directly measure the contents of the black box. In psychology, this may be achieved in two ways: directly, through the use of various neuroimaging technologies, and analogously, through the invasive (generally surgical) manipulations of non-human animals. While there is not nearly sufficient space here to discuss the valuable psychological insights that have been gathered through these respective methods (for some key topics, see: Stevenson and Goldworth, 2002; Bennett and Hacker, 2003; Tashiro, 2004; Filler, 2009; Dietrich and Kanso, 2010), for the specific purpose of theory-building their utility is none-the-less akin to that of standard observation-based methods. While many intuitively assume that the real-time outputs of fMRI scans provide privileged access to the content of the mind, neuroimaging technologies only provide us with activity patterns, which while potentially closely correlated with the informationtransformations of the mind, do not constitute direct measurement of the phenomena in question (Caplan, 2009). Even if neuroimaging techniques were so technologically refined as to accurately discern specific action potentials and the dynamic dendrite configurations of individual neurons, the interpretation of 
these patterns into meaningful psychological content could still only be achieved via detailed correlation with some other source of insight into said processes (Bennett and Hacker, 2003). Though immensely instructive, these methods cannot side-step the fundamental difficulties of hypothesis-testing, but rather can only be taken alongside psychological testing as means of refining existing hypotheses (Caplan, 2009; Filler, 2009).

The second option for refining theories independent of testing involves the use of logical inference to determine what must be the necessary minimum requirements of the systems in question, assuming that said systems are physically internally consistent. This method is extensively employed in computational cognitive psychology (Fodor, 1975, 1983), and is the guiding heuristic of all computational models (Neisser, 1967; Boden and Mellor, 1984; see chapter 4 of Boden, 2006 for a wider historical context). While insufficiently discriminative in their own right, such logical inferences become vastly more powerful when supplied with alternative insights into the limitations of the psychological processes in question (for example, basic neurological insights into the properties of neurons and regional clusters of the brain).

The third, and perhaps final option for refining explanatory theories, is the independent discovery of design details (Lewens, 2002). In mechanical and electrical engineering, such insights may take the form of early blueprints, listing all available materials and tools, or learning what objectives a system was designed to implement (Dorst and Cross, 2001). In a manner wholly analogous to engineered design by humans, abundant evidence suggests that all organisms were designed (Dawkins, 2009), over a geological timescale, by a range of algorithmic evolutionary forces [see chapter 8 of Dennett (1995a), for further details].

Reliance upon details indicative of the design process is the central principle of the adaptationist approach, and is thus the heuristic core of evolutionary psychology (Buss, 2005). While embracing the adaptationist approach is not strictly necessary to gain some of the crucial benefits of the third aforementioned option (indeed any biological, medical, and developmental insights into the properties of the nervous-system provide powerful tools for use with the second and third), the adaptationist approach is designed to draw as much theory-guiding information as possible from the reciprocal relationships of form versus function. Stated simply, adaptationist heuristics regard what a mind is (structurally) as being intimately related to what a mind does (functionally), by in turn acknowledging that how a mind functions has been shaped by why it functions, in a Darwinian sense (Hodgson and Knudsen, 2008).

\section{REVERSE-ENGINEERING AND ADAPTATIONISM}

The paradigm of evolutionary psychology is primarily concerned with explanation, and this orientation has formed the basis of its conceptual incompatibility with the most prominent domains of differential psychology. By examining the explanatory methods employed in evolutionary research, the authors will demonstrate, by contrast, the explanatory short-cuts that have become entrenched in differential psychology, which keep differential researchers at odds not merely with adaptationists, but with theoretically robust psychology in general.

\section{THE GUIDANCE OF DESIGN}

The adaptationist approach is the defining aspect of any work of evolutionary psychology (Sober, 2000; Buss, 2005). An adaptation (when used as a noun) is understood to be a feature or set of features of an organism, the apparent design or concerted complexity of which suggest that it is a product of natural selection, and thus represents a relational calibration of said organism to its ancestor's recurring environmental challenges (Tooby and Cosmides, 2005). At the heart of this paradigm is the suggestion that the species-typical behavioral and cognitive regularities of animals (of humans in particular), likely consist of, or are actively shaped by, adaptations.

Evolutionary psychologists focus on adaptations primarily for pragmatic, explanatory reasons. While all organisms are the products of natural selective forces (and artificial selection in domesticated species), not all features of organisms are adaptations. In the words of Tooby and Cosmides (2005, p. 25,26):

The cross-generationally recurrent design of an organism can be partitioned into (1) adaptations, which are present because they were selected for, (2) by-products of adaptations, which were not themselves targets of selection but are present because they are causally coupled to or produced by traits that were, and (3) noise, which was injected by the stochastic components of evolution.

For reasons of logical necessity, it is nearly impossible to use any positive criteria to confirm that some biological or psychological characteristic is either a by-product or phylogenetic noise. However, a feature can generally be identified as an adaptation when it shows contextual evidence of 'good design' with relation to the adaptive problem or problems it is hypothesized to address (Dennett, 1995a; Buss, 2005).

Functionally speaking, adaptations are relations between organism characteristics and the fitness demands which statistically favored those characteristics in their gene-pool (Dennett, 1995a; Sober, 2000; Dawkins, 2009). Thus, no trait can be accurately described as an adaptation in the absence of this feature-problem matching. For this reason, adaptationists approach complex features with the postulation of possible adaptations, moving on to the possibilities of by-products and noise when the evidence for adaptation is lacking or inadequate (Tooby and Cosmides, 2005). The tell-tale signs of biological design are the clues used by evolutionary psychologists to generate and refine theories about the probable structure and development of a psychological adaptation, utilizing the intrinsic relationships between the form and function of a well-designed system (Dennett, 1995a; Pinker, 1997, 2002; Tooby and Cosmides, 2005). Investigations of this sort are appropriately referred to as "reverseengineering" (Buss, 2005), though it is worth noting that in seeking to gain insight into black box structures through inference from observable input-output contingencies, one could easily argue any psychologist employing explanatory theories is, by necessity, a reverse-engineer (Dennett, 1995b).

\section{LITERAL STRUCTURES DEFINED BY FUNCTION}

Evolutionary theory regards the "mind" as a coordinated system of fitness-enhancing problem-solving apparatus. These hypothesized adaptations are specified to strictly consist of computational neurophysiological structures (Crawford, 2000; Cosmides and 
Tooby, 2001; Tooby and Cosmides, 2005). The existence, performance, and related properties of these adaptations are predicated upon the function they were selected for (Sappington, 1990; Keri, 2003). This focus on information-processes clearly lends itself to many process models in psychology, while many other targeted phenomena in psychology, such as intrinsic 'traits' (Church et al., 2006), internal representations (Fuhrman and Boroditsky, 2010), and qualitative mental states (Markus, 1998), can be understood as calibrated components, products, and observation-level descriptions of psychological processes (see Buss, 2005 for further detail). In contemporary evolutionary psychology, such structures are defined as psychological mechanisms, commonly further designated into processing "modules" (see Buss, 1995; Cosmides and Tooby, 2005, concerning the Massive Modularity Hypothesis).

This account of causally-integrated psychological mechanisms is vital to the conceptual lexicon of evolutionary psychology, and sets a clear yet inclusive standard for the compatible expression of any scientifically viable explanatory psychological construct (including those not thought to be adaptations). The viability of proposing such structures depends largely on evidence found in concerted phenotypic function. As such, the adaptationist approach also provides a unique means of bridging the gap between literal and non-literal construct-based theories, because any construct that is defined by its function is conceivable and testable as a literal, neurophysical psychological mechanism (Dennett, 1995b). Despite these evident benefits, it is precisely this concept of psychological mechanisms, and the detailed explanatory approach that such a conception demands, that is responsible for the much of incompatibility between the theories and approaches of evolutionary and differential psychology.

\section{TOP-DOWN EXPLANATIONS AND DESCRIPTIVE CONSTRUCTS}

There is perhaps no more fitting a characterization of differential psychology than as a field that endeavors to be descriptive. The methodologies and conceptual-tools of differential psychology are supremely well-adapted to the tasks of summarizing and extracting the statistical cores of behaviorally-recurrent trends in populations. With such immense statistical credentials, differential psychology is considered perhaps the greatest beneficiary of the above-mentioned quantitative imperative in behavioral science (Michell, 2003a). Indeed, researchers routinely seek to establish the real-world relevance of theory-based explanatory models (particularly concerning cognitive abilities and personality traits) through the use of differential descriptive constructs. It is telling that the opposite is only very scarcely the case.

The most prominent constructs in differential psychology, the general factor of intelligence " $g$ " and the largely orthogonal personality trait dimensions of the Five Factor Model, were founded with few-or-no explanatory tasks in mind (Meehl, 1998; Lubinski, 2000), and have built their reputations instead on robust statistical properties and impressive correlations with life-outcomes. The " $g$ " construct is an illustrative example, for contrary to common opinion, $g$ is not an explicitly (linguistically) defined construct that is supported by a nexus of covarying statistical trends between many measures. Instead, " $g$ " is simply a name given to a robust statistical nexus of covariation (Lubinski, 2000). Similarly, the orthogonal factor structures of the Five Factor Model of personality take precedence over any worded definition of the factors in question, in a sense making the definition of the factors intrinsically and permanently subject to interpretation (Cattell, 1996; McCrae and Costa, 1999; Grucza and Goldberg, 2007).

The esteem and popular use of such descriptive constructs has, however, led to their insertion into domains that do not match their original intentions or conceptual strengths. While differential descriptive constructs have proven their value through predictive correlations with achievement and outcome measures (Lubinski, 2000), in recent decades the literature has seen the rise and growing acceptance of individual differences papers which employ said descriptive constructs as proposed causative agents in simple explanatory theories (see Boag, 2011 for a detailed account). This form of explanation-description substitution produces a range of far-reaching conceptual problems, particularly with regard to circular reasoning and reification. As the following examples demonstrate, there are limited circumstances in natural science where empirical inquiry into antecedent causes cannot continue, and detailed description is embraced as a surrogate form of explanation. This explanatory approach is viable for only a minority of natural phenomena, and is intrinsically ill-suited for psychology and cognitive science.

\section{LIMITING CASES}

When utilizing descriptive constructs in the role of causative agents, one is relying upon the assumption that reliable trends in observable behaviors are indicative of specific causal forces, be they agents or merely "laws" of expression (Boring, 1950). While this assumption is far from unheard of in some natural sciences, the subject matter of many scientific fields are not nearly as obfuscated by the black box limitations inherent to psychology. For two examples, consider the well-regarded fields of classical molar chemistry and moderate-scale Newtonian physics (Kitcher, 1985). These two fields have enviably few ambiguities in their subject matter, provided they are measured with sufficiently accurate instruments. Subsequently, both molar chemistry and Newtonian physics are founded upon reliable explanatory 'laws', such as GayLussac's law or the Law of Universal Gravitation, all of which were discovered essentially atheoretically through the logical induction of observable trends. While these inquiries yielded theories, they did not require any assumed theoretical framework to undertake. In the terminology advocated by Cervone (1999, 2004, 2005), the explanatory method employed in these two examples, and subsequently misemployed when employing descriptive psychological constructs in explanatory roles, is referred to as topdown explanation (see also Kitcher, 1985; Salmon, 1989; Glennan, 2002).

Top-down explanation relies upon the induction of reliable, structural trends and distinctions, based purely on observational regularities. Of particular interest to psychologists, research programs that employ a top-down explanatory approach are directly compatible with population-level data, as inductions are best made statistically from a wide pool of nomothetic observations. In some sciences, such as chemistry and physics, sufficiently robust observational trends can be reliably assumed to correlate 
with fundamental causal forces, but such accounts are minority cases not to be confused with the wider sense of explanation, which relies upon giving accounts of causal antecedence (explored in-depth in Kitcher, 1985).

In the example of the Law of Universal Gravitation, Newton described in great detail the patterns of relative moment between bodies with mass, and ascribed the name gravity to the consistencies observed (Keesing, 1998). Thus in Newton's model, it is true that positing the force of gravity successfully explains the movement of objects with mass (within particular limits), but the phenomena of gravity itself remains merely described, and not explained at all. To this day, physicists struggle with competing theories in an effort to give a substantial antecedent-based explanation of gravitation and mass, but in Newton's era the viable limit of inquiry had been reached, and it was enough to say that the explanatory effort could end at a detailed description of the most fundamental accessible cause. Though such reasoning is inescapably circular, this description-explanation substitution was accepted due to the immense regularity of the patterns being observed, and because the phenomena in question are so fundamental and causally inscrutable, that the act of reification would not result in the premature dismissal of accounts of true causal antecedents. In psychology, however, this is far from the case.

\section{MISAPPLICATION}

The most prominent contemporary example of descriptive constructs being invoked as top-down explanations of behaviors, are those centered on the Five Factor Model of personality (McCrae and Costa, 1994, 1997). The problems with attempting to use super-ordinate traits in this manner are two-fold: Firstly, psychological phenomena do not meet the conditions of simplicity and observational clarity required to employ an empirically coherent top-down analysis, as most relevant behaviors demand some interpretation or contextual inference to be studied (De Los Reyes and Kazdin, 2008). Human (and animal) behaviors are the result of many cumulative causal forces, whose patterns and configurations cannot in any way be directly induced from observable behavioral trends (Cervone, 2004, 2005). Second, these super-ordinate personality traits are proposed as explanations of the very behaviors that they are aggregated from. This represents internally-inconsistent circular reasoning, as a discrete phenomenon cannot be coherently understood to cause itself (Skinner, 1953; Hanson, 1958; Nozick, 1981; Bandura, 1999; Cervone, 2005; for a more complete treatment of the logical inconsistencies and reification errors in personality trait models, see Boag, 2011).

While the aforementioned conceptual problems are readily identified by those familiar with cases of circular reasoning, attention must also be drawn to the practical and methodological barrier between said constructs and explanatory theories in psychology. Although differential psychologists can and do utilize repeated-measures and other within-persons approaches, the majority of popular descriptive constructs are derived nomothetically, based upon between-persons patterns within sampled populations, and are thus befittingly labeled "difference variables" (Lubinski, 2000). Generally, these population-level variables are presumed to serve as indicators of some intrapersonal factor that determines an individual's contribution to the variation within a group, but as is pointed out by Borsboom and Dolan (2006), such assumptions cannot be embraced without empirical support. To simply presume equivalence between hypothetically related variables, when one exists on the individual-level and the other on the population-level, is conceptually unsound. These conceptual problems compound even further the more aggregated or abstracted a construct is from direct behavioral measurements. A clear example of this conceptual error can be found in the works of Kanazawa (2010a), which investigate "intelligence" as an adaptation for negotiating evolutionarily novel stimuli, while relying methodologically upon the general factor $g$ (Kanazawa, 2006a,b,c, 2007; Lynn and Kanazawa, 2008; Kanazawa and Perina, 2009; Kanazawa and Reyniers, 2009; Kanazawa, 2010a,b). Kanazawa's theories presuppose the existence of a mechanism of general problem-solving, which is further assumed to correlate with population-level intelligence-differentials so closely that the $g$ construct can be taken as its direct measure. As Borsboom and Dolan (2006) demonstrate, neither the probable existence of this mechanism, nor its presumed correlation to $g$ have any substantive empirical or theoretical support. Conversely there are also a number of compelling reasons to believe that domain-general problem-solving mechanisms of the sort described cannot exist coherently in a computational framework (see Penke et al., 2011 for details). Kanazawa's use of $g$ illustrates precisely the kinds of conceptual errors that arise when the untenable "top-down" explanatory approach native to differential psychology attempts direct integration with more robust theories, which rely upon a "bottom-up" approach to explanation.

\section{BOTTOM-UP EXPLANATIONS AND PROCESS MODELS}

In contrast to top-down explanatory methods, Cervone (1999, 2005) also speaks of their conceptual opposite, called simply "bottom-up" explanation. This is the form of explanation predominantly referenced throughout this paper, and is the approach required by adaptationism. Bottom-up explanations are comprised of either literally specified causal antecedents, or functionally-defined approximations of possible literal causal antecedents, hypothesized to underlie the phenomena of interest (Cervone, 2005). To varying degrees, all process models in psychology (specified at the level of an individual) are designed to employ a bottom-up explanatory approach, as they rely upon establishing the counterfactual causes of the phenomena in question (Edwards and Jaros, 1995). There are, however, two key conceptual limitations to the use of classical process models in seeking bottom-up explanations. The first issue concerns the relative completeness of a process account, while the second concerns the difficulty in addressing the first issue via the integration of multiple models.

\section{INCOMPLETE AND INCOMPATIBLE}

Process models have been proposed to describe innumerable specific domains of cognition: the expression of innate temperaments (Richards, 1986; Eysenck, 1994; Mauer and Borkenau, 2007; Aron et al., 2010), the formation of attitudes (Tybout and Scott, 1983; Park et al., 2007), detail-extraction in perception (Marslen-Wilson and Warren, 1994; Vandenbroucke et al., 
2009; Wascher and Beste, 2010), and in social learning processes in general (Bandura, 1986, 1989), to name only a few. Each of these examples demonstrates that strong theories of probable internal operations can (and must) be induced from a wide variety of formative and design-related clues. However, each theory is also fundamentally incomplete when considering the black box nature of the mind. In order to be reliably scrutinized via hypothesis-testing, a theory should account for at least some form of influence at all relevant stages of information-transformation between input stimuli and behavioral output. For example, a process account of reacting to a perceived stimuli should give some consideration to each stage of influence, from perception, to recognition, to motivation, to contemplation, and finally to expression, because variations at any of these levels would fundamentally change the observed input-output contingencies. While such a task may be impossible to achieve in exhaustive detail, and no theorist could be reasonably held to so lofty a standard, the more complete a theory's account of the causal sequence is, the lower the chances that some overlooked variable might skew or invalidate the results.

An intuitive solution to this issue would be to rely on existing process models of related psychological phenomena to supplement those points in a model where intervention would be meaningful. Unfortunately, the persistence of this problem can be largely attributed to issues of terminology, which present an obstacle to integration. Even those processes whose causal pathways of interest may appear mutually compatible are often kept separate by the incompatible referential terminologies of the fields from which they originate (Henriques, 2003). For example, Ho and Fung (2011) published a detailed process model of forgiveness, designed to account for some cultural influences on when and how forgiveness occurs and is displayed. By defining the process of forgiveness in terms of changes in affect and appraisal toward a transgressor, Ho and Fung adopted a functional approach well-suited to cross cultural comparisons, allowing for the simultaneous consideration of emotion, motivation, and other cognitions (for background on this approach, see Enright and Fitzgibbons, 2000). While this model does well by considering a wide variety of potential points of influence in the forgiveness process, some stages (deliberation and expression, in particular) are construed in such a manner as to leave their relationship to other published models vague. Rather than indicating how related models overlap with the stages described, or alternatively, justifying why the existing distinctions prevalent in the literature are inappropriate in this context, both interpretations appear potentially viable. For example, the model (p.79) defines a process of "dialectical thinking" as a major stage in forgiveness, but gives limited elaboration on what this consists of. From the descriptions, dialectical thinking appears to involve comprehension and attribution, cognitions that have also been addressed with cognitive process models in recent years (Rosset, 2008; Ali et al., 2011). Unfortunately, the authors neither acknowledge this potential overlap, nor explain why the terminology used is to be preferred. It seems that the possibility of integration was simply not considered, and that the distinctions employed in this model are idiomatic to the research task. Similarly, the forgiveness model accounts for cultural sources of variance in the emotion-negotiation and expression of forgiving sentiments, but not in a manner immediately compatible with prevailing process models of emotion-regulation (Ochsner and Gross, 2008; Thiruchselvam et al., 2011). It seems that with several basic changes to the defining terminology, this model of forgiveness could potentially be integrated with models of related phenomena, to yield testable predictions in far more substantive detail. Such conceptual clashes are par-for-the-course in psychology research, with only a minority of new theories showing explicit aspirations for wider integration (see Sheldon, 2011, as an example).

\section{INTEGRATION THROUGH ADAPTATIONISM}

The paradigm of evolutionary psychology offers a valuable potential solution: the standardization of referential language into the terminology of modern computational cognitive psychology (Cosmides and Tooby, 2000). An adaptationist theory must be either functionally-oriented toward behavioral outcomes, or hypothesize directly about literal psychological mechanisms. As such, employing evolutionary terminology ensures that effectively any process theory can be expressed in a manner highly compatible with many (and potentially all) other psychological mechanisms (Buss, 2005). Unlike other more abstract procedural concepts, adapted psychological mechanisms are conceptually primed to integrate on the basis of function (see Tooby and Cosmides, 2005 for further discussion). Beyond this, adaptationists can qualify meaningful predictions purely on the level of manifest behavior, because any well-designed adaptation must not interfere with the successful engagement of other mechanisms, except in explicit conditions of evolutionary mismatch (explained further in Cosmides and Tooby, 2001). In these two ways, the grounding theories of evolutionary psychology allow for potentially any process-based theory to be incorporated into more complete, conceptually sound, bottom-up theories. As such, adaptationist theories demonstrate a conceptual interplay between descriptive and explanatory tasks not commonly seen psychological science.

\section{THE EVOLUTION OF INDIVIDUAL DIFFERENCES}

As was explored in the preceding sections, the prevailing methods in differential psychology cater specifically to the scientific task of description, and are thus not only theoreticallyimpoverished with regard to explanation, but appear irreconcilable with more theoretically-robust approaches (Anderson, 2005; Muncer, 2011). These arguments are not to be taken as a general indictment of differential psychology, which remains a highly successful and instructive descriptive enterprise, but merely as a warning and reminder that topdown explanations are scientifically ill-suited to psychological phenomena.

The descriptive nomothetic data provided by prominent differential psychology constructs are commonly designed for highly generalized predictions of outcomes, rather than to provide details that disambiguate the mysteries of particular explanatory models (Lubinski, 2000). This explanatory neutrality represents the primary obstacle to researchers hoping to harness statistically powerful descriptions in aid of explanatory hypothesis-testing. 
Such researchers must struggle to interpret the meaning of quantitative differences that, as explored above, often do not easily map onto linguistic definitions (Cervone, 1999, 2004, 2005). If theorists hope to modify descriptive constructs to better inform causal explanations, population-level behavioral variations must be measured in a manner more indicative of the intrapersonal variables suspected to cause them (Borsboom and Dolan, 2006). That is to say, individual-differences measures must be adjusted so as to preserve (rather than control or mask) individual-level details that map onto the relevant features of explanatory theories. Without such considerations, any research paradigm seeking to bridge the gap between its specific hypotheses and the wider observations of differential psychology, must struggle in vain to match those elements in their explanatory theories thought to produce systemic variations, to the form said variation is expected to take on a generalized behavioral level.

Though some integration efforts have endured for decades (Buss, 1984, 2009), only in recent years have leading evolutionary psychologists embraced the task of modifying and expanding traditional adaptationist theories, in order to account not only for sources of random variation, but also variations preserved or arising from selective forces (Tooby and Cosmides, 1990; Confer et al., 2010; Buss and Hawley, 2011). The following section briefly details some recent expansions of evolutionary theory into areas once thought to be the exclusive purview of classical differential psychology.

\section{WHEN SELECTION MAINTAINS VARIATION}

Since the infancy of evolutionary psychology, Buss (1984, 1991, 1995,2009 ) has explored the concept that a species may evolve a species-typical suite of adaptive interaction strategies (rather than a single "one size fits all" strategy), which are activated or deactivated developmentally as a means of calibrating an individual to the to the particular adaptive challenges of their lifetime (see also, Marsh and Boag, 2010). Despite the promise of this conception with regard to understanding personality psychology, this model presupposed a complex adapted system whose existence must be second-order to, and in principle shaped-by, the more basic selective influences thought to also produce systemic variation (Buss and Greiling, 1999). As such, the greatest advances over the past 10 years of variation-focused evolutionary psychology have comprised a range of sophisticated conceptual and empirical syntheses, aimed at exploring nuanced and often-overlooked Darwinian effects on the cognitive and dispositional properties of human individuals (Michalski and Shackelford, 2010). Speaking broadly, three largely distinct selective phenomena have been refined as viable sources of systemic individual differences in evolved psychology: First, that some dispositions and tendencies represent selectively-neutral or frequency-dependent fitness tradeoffs (as in the case of some personality traits). Second, that some abilities vary due their configural sensitivity to mutation-selection balance (as in the variables of human intelligence). Lastly, in accordance with Buss's founding insights, some psychological phenomena may vary as a function of niche-selecting mechanisms, be they cognitive or epigenetic. This final conception of variation remains largely in its infancy, and will not be discussed at length here (for a wide overview of the potential impact of this perspective on both addressing and redefining psychopathology, see Kennair, 2011).

With regards to fitness tradeoffs, early research (see Buss, 1995) investigated the influence that highly flexible, rapidly-changing environments, would likely have on the slow inter-generational process of trait-favoring selection in a population. Analysis suggests that some human ancestral environments may appear selectively-neutral by virtue of selective pressures either frequently changing, or being too contingent on intra-generational factors (see Belsky, 1999 for summary). This analysis was enriched by increasingly sophisticated tradeoff theories, hypothesizing that the fitness optima of highly variant traits are in fact their "moderate" as opposed to "high" levels, since extremes along many trait continuums are likely to confer maladaptive side-effects (see Keller and Miller, 2006; Nettle, 2006; Penke et al., 2007a,b; Ellis et al., 2009,for details). Building on these insights, theorists were able to account for the selective value of some seemingly disadvantageous, yet common, behavioral tendencies (such as those related to both competitive and altruistic social compulsions) via the inclusion of costly signaling theory (see Miller, 2007 for review) and life-history considerations (see Kaplan and Gangestad, 2005 for relevant discussion). These investigations gave rise to the study of frequency-dependent selection, wherein some variations are understood to be differentially effective based on the distribution of the same and other strategies employed by other members of the population (see Penke et al., 2007a,b for an introduction). With this wealth of insights, evolutionary psychologists now possess a sufficiently nuanced understanding of the selective pressures that likely underlie much of the systematic variation in personality and preference (Keller and Miller, 2006; Penke et al., 2011; Nettle, 2011).

In contrast, the traditional conception of adaptive optimization still appears to be relevant in studying the variations found in cognitive abilities and intelligence. Unlike variations in personality or preference, there appear to be very few tradeoffs or contingent circumstances that render higher levels of ability anything but an unambiguous enhancement of global fitness (Penke et al., 2007a). Fortunately, technological and analytical advances in population genetics have allowed the once-elusive concept mutation-selection balance to applied to the study of cognitive ability (Keller and Miller, 2006; Penke et al., 2007a,b). It has long been understood that the vast majority of natural mutations between the generations of a species tend to impair the collective functioning of their evolved adaptations. It is the ongoing role of natural selection to counteract this accretion of deleterious mutations by selecting against individuals with the greatest accumulation of impairments (individuals with a high effective "mutation-load"). The specific relevance of this phenomenon to cognitive abilities is due to the vulnerability of complex neurological adaptations to relatively small genetic impairments (Michalski and Shackelford, 2010). Since the configuration and optimization of complex psychological adaptations rely upon many structural and developmental provisions, the collective influence of many coordinated genes and expressionfactors contribute to the formation of the delicate final product. Small changes to structural characteristics or enzyme efficiencies 
can thus result in measurable reductions in the calibrated efficiency of the overall mechanism (Keller and Miller, 2006). Thus, mutation-selection balance suggests that the majority of ordinal variation observed in the heritable characteristics of "intelligence," are due largely to negative influences of mutation-loads not yet "filtered-out" by the omnipresent pressures of selection (Penke et al., 2007b), which in-turn partially explains some oncemysterious correlates of intelligence, including general health, vascular development, and body symmetry (Penke et al., 2011).

\section{FINDING VARIATION WITHIN MECHANISMS}

The conceptual tools are now available to other researchers, including career differential psychologists, to begin bridging the divide between evolutionary intra-personal models and traditional individual differences methods. By engaging with explanatory process models, and building upon the elements of those models which permit of individual variations (both as heritable genetic biases or ontogenically calibrated strategies), new causally-relevant hypotheses can be tested with only minor modifications to existing psychometric techniques. Although the above-discussed modes of variation will likely be alien those without an evolutionary background, it is now well within the reach of differential psychologists to apply their methodological expertise, on both individual and population levels, to enriching even relatively simple process-based evolutionary theories.

The key to such efforts, however, is to embrace the lack of relevance most popular differential psychology constructs have to explanatory hypothesis-testing, and working to produce intermediary measurement tools and approaches that can bridge between the predicted variations within a process model, and what form said variation can be expected to take on an overt behavioral level. A strong example of this kind of research can be found in the social rank/dominance and social-exchange measures developed by Leybman and associates (Zuroff et al., 2010; Leybman et al., 2011a,b). Although the various incarnations of these measures resemble, both in presentation and in statistical verification, traditional differential psychometrics, fundamental design distinctions were taken directly from existing evolutionary process models of how humans negotiate reputation-sensitive social exchanges. Rather than creating and factor-analyzing a pool of items, with the goal of retroactively assigning descriptive titles to the factors that emerge, each element of the measures was intended to capture particular sources of intra-personal variation in the theorized psychological mechanisms, and their statistical validity was judged by how well response-patterns reflected this. Not only are these measures of dominance and social-exchange primed for testing hypotheses pertinent to the explanatory theory they are inspired by, their correlations with other descriptive constructs designed purely on the population-level can further inform an understanding of how intra-personal variations shape (and in the case of frequency-dependent selection, interact with) the overall diversity of the population (Leybman et al., 2011a).

In addition to providing more causally-relevant theoretical structures for the examination of variations already explored at the individual and population level, evolutionary-differential integration may also, on occasion, permit insightful conceptual revisions of some individual differences phenomena that have otherwise eluded explanation. For example, by expanding beyond the initial efforts of Rushton (1985, 2000, 2004), Figueredo and colleagues have developed a new approach to studying the General Factor of Personality (GFP), which utilizes life history strategy as the ultimate factor organizing the seemingly diffuse traits and behaviors observed (see Figueredo et al., 2005; Figueredo and Rushton, 2009). Beyond offering an account of the general organization of personality traits relating to social functioning, this approach has yielded a range of novel predictions concerning how ontogenic calibrations of life history strategy, such as degree of parental support, shape variation in GFP (van der Linden et al., 2012). Similar life history approaches have recently been applied to other domains of normative variation that have eluded simple explanation, including the clustering of several cognitive aptitudes and personality traits [as explored in Woodley et al. (2013)], and the human stress response system (see Del Giudice et al., 2011, for theoretical framing of the model, and Del Giudice et al., 2012, for promising empirical support). Each of these examples demonstrates a collection of psychological phenomena that had been successfully identified top-down as a reliable pattern of variation by differential psychologists, but which eluded explanation and a source of novel predictions in the absence of a functional account of evolved psychological mechanisms.

\section{CONCLUSION}

In closing, this article has explored both the historical origins and contemporary impact of a perceived incompatibility between differential and evolutionary psychology, within the wider context of the unique challenges psychology faces as a science. The core of this incompatibility can be traced to confusions over, and a lack appreciation for, the distinct scientific tasks of description and explanation. Exclusive specialization in quantitative descriptive statistics has left differential psychology institutionally powerful, but theoretically-impoverished and conceptually isolated, with only limited means of applying its descriptive prowess to causal explanatory models. Evolutionary psychology has demonstrated a range of empirical and conceptual strengths that support its suitability as an integrating platform for functional cognitive and behavioral science. This strength has most recently manifested as a series of sophisticated and highly successful attempts to expand into the territories of differential psychology, thus establishing a range of innovative new means of describing and explaining the underlying causes of individual differences.

Researchers now have the foundations laid for them to develop new, theoretically-rich descriptive tools which can contribute directly to the hypothesis-testing of explanatory process models. Particularly when utilizing the heuristic tools of evolutionary psychology, even researchers inexperienced with adaptationism can work to bridge the conceptual gaps between our theories of functional, psychological mechanisms, and our accounts of tendencies and abilities in individuals and the population at large. 


\section{REFERENCES}

Ali, N., Chater, N., and Oaksford, M. (2011). The mental representation of causal conditional reasoning: mental models or causal models. Cognition 119, 403-418. doi: 10.1016/j.cognition.2011.02.005

Allen, G. (2002). The measure of a Victorian polymath: pulling together the strands of Francis Galton's legacy to modern biology. Nature 145, 19-20. doi: $10.1038 / 415019 a$

Anderson, M. (2005). "Marrying intelligence and cognition: a developmental view," in Cognition and Intelligence: Identifying the Mechanisms of the Mind, ed R. J. Sternberg (Cambridge: Cambridge University Press), 268-287. doi: 10.1017/CBO9780511607073.015

Aron, A., Ketay, S., Hedden, T., Aron, E. N., Markus, H. R., and Gabrieli, J. D. E. (2010). Temperament trait of sensory processing sensitivity moderates cultural differences in neural response. Soc. Cogn. Affect. Neurosci. 5, 219-226. doi: $10.1093 /$ scan/nsq028

Astbury, B., and Leeuw, F. L. (2010). Unpacking black boxes: mechanisms and theory building in evaluation. Am. J. Eval. 31, 363-381. doi: $10.1177 / 1098214010371972$

Baars, B. (1984). View from a road not taken. Contemp. Psychol. 29, 804-805.

Baars, B. (1985). The logic of unification. Contemp. Psychol. 30, 340.

Bandura, A. (1986). Social Foundations of Thought and Action: a Social Cognitive Theory. Englewood Cliffs, NJ: Prentice-Hall.

Bandura, A. (1989). "Social cognitive theory," in Annals of Child Development, 6: Six theories of child development, ed R. Vasta (Greenwich: JAI Press), 1-60. doi: 10.1037/0003-066X.44.9.1175

Bandura, A. (1999). "Social cognitive theory of personality," in The Coherence of Personality: SocialCognitive Bases of Consistency, Variability, and Organization, eds D. Cervone and Y. Shoda (New York, NY: Guilford Press), 185-241.

Barkow, J. H., Cosmides, L., and Tooby, J. (1992). The Adapted Mind: Evolutionary Psychology and the Generation of Culture. New York, NY: Oxford University Press.

Baum, W. M. (1994). Understanding Behaviorism: Science, Behavior, and Culture. New York, NY: Harper Collins.

Beizer, B. (1995). Black-Box Testing: Techniques for Functional Testing of Software and Systems. New York, NY: John Wiley and Sons. Inc.
Belsky, J. (1999). "Modern evolutionary theory and patterns of attachment," in Handbook of Attachment: Theory, Research, and Clinical Applications, eds J. Cassidy and P. R. Shaver (New York, NY: Guilford), 141-161.

Bennett, M. R., and Hacker, M. S. (2003). Philosophical Foundations of Neuroscience. Oxford: Blackwell.

Bergman, L. R., and Trost, K. (2006). The person-oriented versus the variable-oriented approach: are they complementary, opposites, or exploring different worlds? Merrill-Palmer Q. 52, 377-389. doi: 10.1353/mpq.2006.0023

Block, J. (1989). Critique of the act frequency approach to personality. J. Pers. Soc. Psychol. 56, 234-245. doi: 10.1037/0022-3514. 56.2 .234

Block, J. (2010). The five-factor framing of personality and beyond: some ruminations. Psychol. Inq. 21, 2-25. doi: 10.1080/10478401003596626

Boag, S. (2011). Explanation in personality psychology: 'verbal magic' and the five-factor model. Philos. Psychol. 24, 223-243. doi: 10.1080/09515089.2010.548319

Boden, M. A. (2006). Mind as Machine: a History of Cognitive Science, Vol. 1. Oxford: Oxford University Press.

Boden, M. A., and Mellor, D. H. (1984). What is computational psychology? Proc. Aristot. Soc. 58, 17-35, 37-53.

Borghans, L., Golsteyn, B. H. H., Heckman, J., and Humphries, J. E. (2011). Identification problems in personality psychology.Pers. Individ. Diff. 51, 315-320. doi: 10.1016/j.paid.2011.03.029

Boring, E. G. (1950). A History of Experimental Psychology. New York, NY: Appleton-CenturyCrofts.

Borsboom, D. (2005). Measuring the Mind: Conceptual Issues in Contemporary Psychometrics. Cambridge: Cambridge University Press.

Borsboom, D., and Dolan, C. V. (2006). Why g is not an adaptation: A comment on Kanazawa. Psychol. Rev. 113, 433-437. doi: 10.1037/0033295X.113.2.433

Borsboom, D., Mellenbergh, G. J., and Van Heerden, J. (2004). The concept of validity. Psychol. Rev. 111, 1061-1071. doi: 10.1037/0033295X.111.4.1061

Bower, G. H. (1993). The fragmentation of psychology? Am. Psychol. 48, 905-907. doi: 10.1037/0003-066X. 48.8.905

Bowler, P. J. (2003). Evolution: The History of an Idea, 3rd, Edn.
Berkeley, CA: University of California Press.

Buller, D. J. (2005). Adapting Minds: Evolutionary Psychology and the Persistent Quest for Human Nature. Cambridge, MA: MIT Press; US.

Bunge, M. (1963). A general black box theory. Philos. Sci. 30, 346-358. doi: 10.1086/287954

Buss, D. M. (1984). Evolutionary biology and personality psychology: toward a conception of human nature and individual differences. Am. Psychol. 39, 1135-1147. doi: 10.1037/0003-066X.39.10.1135

Buss, D. M. (1991). Evolutionary personality psychology. Annu. Rev. Psychol. 42, 459-491. doi: 10.1146/annurev.ps.42.020191. 002331

Buss, D. M. (1995). Evolutionary psychology: a new paradigm for psychological science. Psychol. Inq. 6, 1-30. doi: 10.1207/s15327 965pli0601_1

Buss, D. M. (1999). Evolutionary Psychology: The New Science of the Mind. Boston, MA: Allyn and Bacon.

Buss, D. M. (2009). How can evolutionary psychology successfully explain personality and individual differences? Perspect. Psychol. Sci. 4, 359-366. doi: 10.1111/j.17456924.2009.01138.x

Buss, D. M., Abbott, M., and Angleitner, A. (1990). International preferences in selecting mates: a study of 37 cultures. J. Crosscult. Psychol. 21, 5-47. doi: 10.1177/0022022190211001

Buss, D. M., and Greiling, H. (1999). Adaptive individual differences. J. Pers. 67, 209-243. doi: 10.1111/1467-6494.00053

Buss, D. M., and Hawley, P. H. (2011) The Evolution of Personality and Individual Differences. New York, NY: Oxford University Press.

Buss, D.M. (Eds.), (2005). The Handbook of Evolutionary Psychology. Hoboken, NJ: John Wiley and Sons Inc; US.

Bynum, W. F. (2002). The childless father of eugenics. Science 296, 472. doi: 10.1126/science.1069041

Caplan, D. (2009). Experimental design and interpretation of functional neuroimaging studies of cognitive processes. Hum. Brain Mapp. 30, 59-77. doi: 10.1002/hbm.20489

Cattell, H. E. P. (1996). The original big-five: a historical perspective. Eur. Rev. Psychol. 46, 5-14.

Cervone, D. (1991). The two disciplines of personality psychology. Psychol. Sci. 6, 371-77. doi: 10.1111/j.14679280.1991.tb00169.x
Cervone, D. (1999). "Bottom-up explanation in personality psychology: the case of cross-situational coherence," in The Coherence of Personality: Social-Cognitive Bases of Personality Consistency, Variability, and Organization, eds D. Cervone and Y. Shoda (New York, NY: Guilford Press), 303-341.

Cervone, D. (2004). The architecture of personality. Psychol. Rev. 111, 183-204. doi: 10.1037/0033295X.111.1.183

Cervone, D. (2005). Personality architecture: within-person structures and processes. Annu. Rev. Psychol. 56, 423-452. doi: 10.1146/annurev. psych.56.091103.070133

Chamorro-Premuzic, T., and Furhnam, A. (2006). Intellectual competence and the intelligent personality: a third way in differential psychology. Rev. Gen. Psychol. 10, 251-267. doi: 10.1037/1089-2680.10.3.251

Church, A. T., Katigbak, M. S., Del Prado, A. M., Ortiz, F. A., Mastor, K. A., Harumi, Y., et al. (2006). Implicit theories and self-perceptions of traitedness across cultures: toward integration of cultural and trait psychology perspectives. J. Crosscult. Psychol. 37, 694-716. doi: $10.1177 / 0022022106292078$

Confer, J. C., Easton, J. A., Fleischman, D. S., Goetz, C. D., Lewis, D. M., Perilloux, C., et al. (2010). Evolutionary psychology: controversies, questions, prospects, and limitations. Am. Psychol. 65, 110-126. doi: 10.1037/a0018413

Cosmides, L., and Tooby, J. (1987).

"From evolution to behavior: evolutionary psychology as the missing link," in The Latest on the Best: Essays on Evolution and Optimality, ed J. Dupré (Cambridge, MA: MIT Press), 276-306.

Cosmides, L., and Tooby, J. (1989). Evolutionary psychology and the generation of culture, part II. Case study: a computational theory of social exchange. Ethol. Sociobiol. 10, 51-97. doi: 10.1016/0162-3095(89)90013-7

Cosmides, L., and Tooby, J. (1997) "The modular nature of human intelligence," in The Origin and Evolution of Intelligence, eds A. B. Scheibel and J. W. Schopf (Sudbury, MA: Jones and Bartlett), 71-101.

Cosmides, L., and Tooby, J. (2000). "Evolutionary psychology and the emotions," in Handbook of Emotions, 2nd Edn., eds M. Lewis and J. M. HavilandJones (New York, NY: Guilford), 91-115.

Cosmides, L., and Tooby, J. (2001). "Unraveling the enigma of human 
intelligence: evolutionary psychology and the multimodular mind," in The Evolution of Intelligence, eds R. J. Sternberg and J. C. Kaufman (Hillsdale, NJ: Erlbaum), 145-198.

Cosmides, L., and Tooby, J. (2005). "Neurocognitive adaptations designed for social exchange," in The Handbook of Evolutionary Psychology, eds D. M. Buss (Hoboken, NJ: Wiley), 584-627.

Cramer, A. O. J., Waldorp, L. J., van der Maas, H. L. J., and Borsboom, D. (2010). Comorbidity: a network perspective. Behav. Brain Sci. 33, 137-193. doi: 10.1017/S0140525X09991567

Crawford, C. (2000). Evolutionary psychology: counting babies or studying information processing mechanisms. Ann. N.Y. Acad. Sci. 907, 21-38. doi: 10.1111/j.17496632.2000.tb06613.x

Cronbach, L. J. (1957). The two disciplines of scientific psychology. Am. Psychol. 12, 671-684. doi: 10.1037/h0043943

Daly, M., and Wilson, M. (1999). Human evolutionary psychology and animal behaviour. Anim. Behav. 57, 509-519. doi: 10.1006/anbe.1998.1027

Daly, M., and Wilson, M. (2008). "Is the "Cinderella effect" controversial?: a case study of evolution-minded research and critiques thereof," in Foundations of Evolutionary Psychology, eds C. Crawford and D. Krebs (New York, NY: Taylor and Francis Group/Lawrence Erlbaum Associates), 383-400.

Darwin, C. (1859). The Origin of Species. Oxford: Oxford University Press, 1996.

Darwin, C. (1871). The Descent of Man and Selection in Relation to Sex. London: Gibson Square Books, 2003.

Dawkins, R. (2009). The Greatest Show on Earth: the Evidence for Evolution. New York, NY: Free Press.

de Groot, A. D. (1990). Unifying psychology: a European view. New Ideas Psychol. 8, 309-320. doi: 10.1016/0732-118X(94)90018-3

De Los Reyes, A., and Kazdin, A. E. (2008). When the evidence says, "Yes, no, and maybe so": attending to and interpreting inconsistent findings among evidence-based interventions. Curr. Dir. Psychol. Sci. 17, 47-51. doi: 10.1111/j.14678721.2008.00546.x

Del Giudice, M., Ellis, B. J., and Shirtcliff, E. A. (2011). The adaptive calibration model of stress responsivity. Neurosci. Biobehav. Rev. 35, 1562-1592. doi: 10.1016/j.neubiorev.2010.11.007
Del Giudice, M., Hinnant, J. B., Ellis, B. J., and El-Sheikh, M. (2012). Adaptive patterns of stress responsivity: a preliminary investigation. Dev. Psychol. 48, 775-790. doi: 10.1037/a0026519

Dennett, D. C. (1995a). Darwin's Dangerous Idea: Evolution and the Meanings of Life. New York, NY: Simon and Schuster.

Dennett, D. C., (1995b). Cognitive science as reverse engineering several meanings of "Top-down" and "Bottom-up". Stud. Logic Found. Math. 134, 679-689. doi: 10.1016/S0049-237X(06)80069-8

Dietrich, A., and Kanso, R. (2010). A review of EEG, ERP, and neuroimaging studies of creativity and insight. Psychol. Bull. 136, 822-848. doi: $10.1037 /$ a0019749

Dixon, R. A. (1983). Theoretical proliferation in psychology: a plea for sustained disunity. Psychol. Rec. 33, 337-340.

Dorst, K., and Cross, N. (2001). Creativity in the design process: co-evolution of problem-solution. Des. Stud. 22, 425-437. doi: 10.1016/S0142-694X(01)00009-6

Edwards, L., and Jaros, G. G. (1995). Psychology, a discipline with a structure-based history and a process-based future. J. Soc. Evol. Syst. 18, 67-85. doi: 10.1016/1061-7361(95)90016-0

Ellis, B. J., Figueredo, A. J., Brumbach, B. H., and Schlomer, G. L. (2009). Fundamental dimensions of environmental risk: the impact of harsh versus unpredictable environments on the evolution and development of life history strategies. Hum. Nat. 20, 204-298. doi: 10.1007/s12110009-9063-7

Enright, R. D., and Fitzgibbons, R. P. (2000). Helping Clients Forgive: an Empirical Guide for Resolving Anger and Restoring Hope. Washington, DC: American Psychological Association. doi: 10.1037/10381-000

Eysenck, H. J. (1994). "The big five or giant three: criteria for a paradigm," in The Developing Structure of Temperament and Personality from Infancy to Adulthood, eds C. F. Halverson, G. A. Kohnstamm, and R. P. Martin (Hillsdale, NJ: Erlbaum), 37-51.

Figueredo, A. J., and Rushton, J. P. (2009). Evidence for shared genetic dominance between the general factor of personality, mental and physical health, and life history traits. Twin Res. Hum. Genet. 12, 555-563. doi: 10.1375/twin.12.6.555
Figueredo, A. J., Vásquez, G. Brumbach, B. H., Sefcek, J. A., Kirsner, B. R., and Jacobs, W. J. (2005). The K-factor: individual differences in life history strategy. Pers. Individ. Dif. 39, 1349-1360. doi: 10.1016/j.paid.2005.06.009

Filler, A. G. (2009). The history, development, and impact of computed imaging in neurological diagnosis and neurosurgery: CT, MRI, DTI. Nat. Preced. doi 10.1038/npre.2009.3267.5

Fisher, R. A. (1925). Statistical Methods for Research Workers. Edinburgh: Oliver and Boyd.

Fitzgerald, C. J., and Whitaker, M. B. (2010). Examining the acceptance of and resistance to evolutionary psychology. Evol. Psychol. 8 , 284-296.

Fodor, J. (1975). The Language of Thought. Cambridge, MA: MIT Press.

Fodor, J. A. (1983). The Modularity of Mind. Cambridge, MA: MIT Press.

Forest, D. (1995). "Francis Galton (1822-1911)," in Seven Pioneer of Psychology: Behavior and Mind, ed R. Fuller (London, New York: Routledge), 1-19.

Fuhrman, O., and Boroditsky, L. (2010). Cross-cultural differences in mental representations of time: evidence from an implicit nonlinguistic task. Cogn. Sci. 34, 1430-1451. doi 10.1111/j.1551-6709.2010.01105.x

Galton, F. (1889). Natural Inheritance. London: Macmillan. doi 10.5962/bhl.title.32181

Garlick, D. (2002). Understanding the nature of the general factor of intelligence: the role of individual differences in neural plasticity as an explanatory mechanism. Psychol. Rev. 109, 116-136. doi: 10.1037/0033-295X.109.1.116

Garlick, D. (2003). Integrating brain science research with intelligence research. Curr. Dir. Psychol. Sci. 12, 185-189. doi: 10.1111/14678721.01257

Gaukroger, S. (2006). The Emergence of a Scientific Culture. Oxford: Clarendon Press. doi: 10.1093/acprof:oso/9780199296446. 001.0001

Gintis, H. (2007). A framework for the unification of the behavioral sciences. Behav. Brain Sci. 30, 1-61 doi: 10.1017/S0140525X07000581

Gladin, L. L. (1961). Toward a unified psychology. Psychol. Rec. 11, 405-421.

Glennan, S. (2002). Rethinking mechanistic explanation. Philos. Sci. 69, 342-353. doi: 10.1086/ 341857
Goertzen, J. R. (2008). On the possibility of unification: the reality and nature of the crisis in psychology. Theory Psychol. 18, 829-852. doi: $10.1177 / 0959354308097260$

Goertzen, J. R. (2010). Dialectical pluralism: a theoretical conceptualization of pluralism in psychology. New Ideas Psychol. 28, 201-209. doi: 10.1016/j.newideapsych.2009. 09.013

Gould, S. J. (1981). The Mismeasure of Man. New York, NY: W. W. Norton and Co.

Gould, S. J., and Lewontin, R. C. (1979). The Spandrels of San Marco and the panglossian paradigm: a critique of the adaptationist programme. Proc. $R$. Soc. Lond. B 205, 581-598. doi: 10.1098/rspb.1979.0086

Grucza, R. A., and Goldberg, L. R. (2007). The comparative validity of 11 modern personality inventories: predictions of behavioral acts, informant reports, and clinical indicators. J. Pers. Assess. 89, 167-187. doi: $10.1080 / 0022389070$ 1468568

Hamilton, W. D. (1954). The genetical evolution of social behaviour. I and II. J. Theor. Biol. 7, 1-52. doi: 10.1016/0022-5193(64)90038-4

Hanson, N. R. (1958). Patterns of Discovery: an Inquiry into the Conceptual Foundations of Science. Cambridge: Cambridge University Press.

Henriques, G. (2003). The tree of knowledge system and the theoretical unification of psychology. Rev. Gen. Psychol. 7, 150-182. doi: 10.1037/1089-2680.7.2.150

Henriques, G. R. (2004). Psychology defined. J. Clin. Psychol. 60 1207-1221. doi: $10.1002 /$ jclp.20061

Henriques, G. R. (2008). The problem of psychology and the integration of human knowledge: contrasting Wilson's consilience with the tree of knowledge system. Theory Psychol. 18, 731-755. doi: 10.1177/0959354308097255

Henriques, G. R. (2011). A New Unified Theory of Psychology. New York, NY: Springer. doi: 10.1007/978-1-46140058-5

Ho, M. Y., and Fung, H. H. (2011). A dynamic process model of forgiveness: a cross-cultural perspective. Rev. Gen. Psychol. 15, 77-84 doi: 10.1037/a0022605

Hodgson, G. M., and Knudsen, T. (2008). In search of general evolutionary principles: why Darwinism is too important to be left to the biologists. J. Bioecon. 10, 51-69. doi: 10.1007/s10818008-9030-0 
House, E. R. (1991). Realism in research. Educ. Res. 20, 2-9. doi: 10.3102/0013189X020006002

Hüttemann, A., and Love, A. C. (2011). Aspects of reductive explanation in biological science: intrinsicality, fundamentality, and temporality. Br. J. Philos. Sci. 62, 519-549. doi: 10.1093/bjps/ axr006

Huxley, J. (1942). Evolution: the Modern Synthesis. New York, NY: Harper and Brothers.

Jaszczolt, K. (1996). Relevance and infinity: implications for discourse interpretation. J. Pragmatics 25, 703-722. doi: 10.1016/0378-2166(94)00104-9

Jensen, A. (2002). Galton's legacy to research on intelligence. J. Biosoc. Sci. 34, 145-172. doi: $10.1017 /$ S0021932002001451

Kanazawa, S. (2006a). Why the less intelligent may enjoy television more than the more intelligent. J. Cult. Evol. Psychol. 4, 27-36. doi: 10.1556/JCEP.4.2006.1.2

Kanazawa, S. (2006b). Mind the gap ...in Intelligence: reexamining the relationship between inequality and Health. Br. J. Health Psychol. 11, 623-642. doi: 10.1348/135910705X69842

Kanazawa, S. (2006c). IQ and the wealth of States. Intelligence 34, 593-600. doi: 10.1016/j.intell.2006.04.003

Kanazawa, S. (2007). The evolutionary psychological imagination: why you can't get a date on a saturday night and why most suicide bombers are muslim. J. Soc. Evol. Cult. Psychol. 1, 7-17.

Kanazawa, S. (2010a). Why liberals and atheists are more intelligent. Soc. Psychol. Q. 73, 33-57.

Kanazawa, S. (2010b). Evolutionary psychology and intelligence research. Am. Psychol. 65, 279-289. doi: 10.1037/a0019378

Kanazawa, S., and Perina, K. (2009). Why night owls are more intelligent. Pers. Individ. Diff. 47, 685-690. doi: 10.1016/j.paid.2009.05.021

Kanazawa, S., and Reyniers, D. J. (2009). The role of height in the sex difference in intelligence. Am. J. Psychol. 122, 527-536.

Kantor, J. R. (1979). Psychology: science or nonscience? Psychol. Rec. 29, 155-163.

Kaplan, A. (1964). The Conduct of Inquiry: Methodology for Behavioral Science. Scranton, PA: Chandler Publishing Co.

Kaplan, D. M., and Craver, C. F. (2011). The explanatory force of dynamical and mathematical models in neuroscience: a mechanistic perspective. Philos. Sci. 78, 601-627. doi: 10.1086/661755

Kaplan, H. S., and Gangestad, S. W. (2005). "Life history theory and evolutionary psychology," in Handbook of evolutionary psychology, ed D. M. Buss (New York, NY: Wiley), 68-95.

Karasek, R. A. (1979). Job demands, job decision latitude, and mental strain: implications for job redesign. Admin. Sci. Q. 24, 285-307. doi: $10.2307 / 2392498$

Kassinove, J. I. (2002). As defined, unification is inevitable. Am. Psychol. 57, 1127 . doi: 10.1037/0003-066X.57.12.1127a

Keesing, R. G. (1998). The history of Newton's apple tree. Contemp. Phys. 39, 377-391. doi: 10.1080/001075198181874

Keller, M. C., and Miller, G. F. (2006). Resolving the paradox of common, harmful, heritable mental disorders: which evolutionary genetic models work best? Behav. Brain Sci. 29, 385-452. doi: 10.1017/S0140525X06009095

Kelly, R. J. (1998). The crisis in psychology: trouble in the temple. J. Soc. Distr. Homeless 7, 211-223. doi: 10.1023/A:1022987813476

Kennair, L. E. O. (2011). "The problem of defining psychopathology and challenges to evolutionary psychology theory," in The Evolution of Personality and Individual Differences, eds D. M. Buss and P. H. Hawley (New York, NY: Oxford University Press), 451-479.

Keri, S. (2003). Genetics, psychology, and determinism. Am. Psychol. 58, 319. doi: 10.1037/0003-066X.58.4.319a

Ketelaar, T., and Ellis, B. (2000). Are evolutionary explanations unfalsifiable?: evolutionary psychology and the Lakatosian philosophy of science. Psychol. Inq. 11, 1-21. doi: 10.1207/S15327965PLI1101_01

Kitcher, P. (1985). Two approaches to explanation. J. Philos. 82, 632-639. doi: $10.2307 / 2026419$

Lamiell, J. T. (2003). Beyond Individual and Group Differences: Human Individuality, Scientific Psychology, and William Stern's Critical Personalism. Thousand Oaks, CA: Sage Publications.

Lewens, T. (2002). Adaptationism and engineering. Biol. Philos. 17, 1-31. doi: 10.1023/A:1012915007444

Leybman, M. J., Zuroff, D. C., and Fournier, M. A. (2011a). A fivedimensional model of individual differences in social exchange styles. Pers. Individ. Diff. 51, 940-945. doi: 10.1016/j.paid.2011.07.024
Leybman, M. J., Zuroff, D. C., Fournier, M. A., Kelly, A. C., and Martin, A. (2011b). Social exchange styles: measurement, validation, and application. Eur. J. Pers. 25, 198-210. doi: 10.1002/per.785

Lubinski, D. (2000). Scientific and social significance of assessing individual differences: "sinking shafts at a few critical points". Ann. Rev. Psychol. 51, 405-444. doi: 10.1146/annurev.psych.51.1.405

Lynn, R., and Kanazawa, S. (2008). How to explain high jewish achievement: the role of intelligence and values. Pers. Individ. Diff. 44, 801-808. doi: 10.1016/j.paid.2007.10.019

Maltby, J., Day, L., and Macaskill, A. (2007). Personality, Individual Differences and Intelligence. London: Pearson Education.

Mandler, G. (2002). Origins of the cognitive revolution. J. Hist. Behav. Sci. 38, 339-353. doi: 10.1002/jhbs.10066

Mandler, G. (2011). Crises and problems seen from experimental psychology. J. Theor. Philos. Psychol. 31, 240-246. doi: 10.1037/ a0023968

Marks, D. F., Murray, M. P., Evans, B., Willig, C., Sykes, C. M. and Woodall, C. (2005). Health Psychology: Theory, Research and Practice. London: Sage Publications.

Markus, K. A. (1998). Psychological processes and mental stability. Am. Psychol. 53, 1077-1078. doi: 10.1037/0003-066X.53.9.1077

Marsh, T., and Boag, S. (2010). "Applying evolutionary theory to individual differences: insights from moral psychology," in Personality and Individual Differences: Current Directions, eds R. E. Hicks (Bowen Hills: Australian Academic Press), 123-134.

Marslen-Wilson, W., and Warren, P. (1994). Levels of perceptual representation and process in lexical access: words, phonemes, and features. Psychol. Rev. 101, 653-675. doi: 10.1037/0033-295X. 101.4.653

Matarazzo, J. D. (1987). There is only one psychology, no specialties, but many applications. American Psychologist 42, 893-903. doi: 10.1037/0003-066X.42.10.893

Matarazzo, J. D. (1992). The unity or diversity of psychology: concluding remarks. Int. J. Psychol. 27, 327-330. doi: 10.1080/00207599208247174

Mauer, N., and Borkenau, P. (2007). Temperament and early information processing: temperament-related attentional bias in emotional stroop tasks. Pers.
Individ. Diff. 43, 1063-1073. doi: 10.1016/j.paid.2007.02.025

McCrae, R. R., and Costa, P. T. (1994). The stability of personality: observation and evaluations. Curr. Dir. Psychol. Sci. 3, 173-175. doi: 10.1111/1467-8721.ep10770693

McCrae, R. R., and Costa, P. T. Jr. (1999). "A five-factor theory of personality," in Handbook of Personality: Theory and Research, eds L. A. Pervin and O. P. John (New York, NY: Guilford Press), 139-153.

McCrae, R., and Costa, P. (1997). Personality trait structures as a human universal. $A m$. Psychol. 52, 509-516. doi: 10.1037/0003-066X.52.5.509

Meehl, P. E. (1978). Theoretical risks and tabular asterisks: Sir Karl, Sir Ronald, and the slow progress of soft psychology. J. Consult. Clin. Psychol. 46, 806-834. doi: 10.1037/0022-006X. 46.4.806

Meehl, P.E. (1998). The Power of Quantitative Thinking. Washington, DC: American Psychological Society Cattell Award Address.

Michalski, R. L., and Shackelford, T. K. (2010). Evolutionary personality psychology: reconciling human nature and individual differences. Pers. Individ. Diff. 48, 509-516. doi: 10.1016/j.paid.2009.10.027

Michell, J. (1990). An Introduction to the Logic of Psychological Measurement. Hillsdale, NJ: Erlbaum.

Michell, J. (2003a). The quantitative imperative: positivism, naïve realism and the place of qualitative methods in psychology. Theory Psychol. 13, 5-31. doi: 10.1177/0959354303013001758

Michell, J. (2003b). Pragmatism, positivism and the quantitative imperative. Theory Psychol. 13, 45-52. doi: 10.1177/0959354303013001761

Michell, J. (2005). The meaning of the quantitative imperative. Theory Psychol. 15, 257-263. doi: 10.1177/0959354305051369

Miller, G. A. (2003). The cognitive revolution: a historical perspective. Trends Cogn. Sci. 7, 141-144. doi: 10.1016/S1364-6613(03)00029-9

Miller, G. F. (2007). Sexual selection for moral virtues. Q. Rev. Biol. 82, 97-125. doi: 10.1086/517857

Mischel, W. (1968). Personality and Assessment. New York, NY: Wiley

Mischel, W. (1973). Toward a cognitive social learning reconceptualization of personality. Psychol. Rev. 80, 252-83. doi: 10.1037/ h0035002

Muncer, S. J. (2011). The general factor of personality: evaluating 
the evidence from meta-analysis, confirmatory factor analysis and evolutionary theory. Pers. Individ. Diff. 51, 775-778. doi: 10.1016/j.paid.2011.06.029

Nairne, J. S. (1997). Psychology: The Adaptive Mind. Pacific Grove, CA: Brooks/Cole.

Neisser, U. (1967). Cognitive Psychology. New York, NY: Meredith

Neisser, U. (1995). The unity of psychology and of persons. Int. Newslett. Uninomic Psychol. 15, 6-12.

Neisser, U., Boodoo, G., Bouchard, T. J. Jr., Boykin, A. W., Brody, N., Ceci, S. J., et al. (1996). Intelligence: knowns and unknowns. Am. Psychol. 51, 77-101. doi: 10.1037/0003-066X.51.2.77

Nesse, R. M., and Lloyd, A. T. (1992). "The evolution of psychodynamic mechanisms," in The adapted mind: Evolutionary psychology and the generation of culture, eds J. H. Barkow, L. Cosmides, and J. Tooby (New York, NY: Oxford University Press), 601-624.

Nettle, D. (2006). The evolution of personality variation in humans and other animals. Am. Psychol. 61, 622-631. doi: 10.1037/0003066X.61.6.622

Nettle, D. (2011). "Evolutionary perspectives on the five-factor model of personality," in The Evolution of Personality and Individual Differences, eds D. M. Buss and P. H. Hawley (New York, NY: Oxford University Press), 5-28.

Nozick, R. (1981). Philosophical Explanations. Cambridge, MA: Belknap Press of Harvard University Press.

Ochsner, K. N., and Gross, J. J. (2008). Cognitive emotion regulation: insights from social cognitive and affective neuroscience. Curr. Dir. Psychol. Sci. 17, 153-158. doi: 10.1111/j.1467-8721.2008.00566.x

Olsson, L., Hobfeld, U., and Breidbach, O. (2006). Preface: from evolutionary morphology to the modern synthesis and "evo-devo": historical and contemporary perspectives. Theory Biosci. 124, 259-263. doi: 10.1016/j.thbio.2005.12.001

Park, H. S., Levine, T. R., Westerman, C. Y. K., Orfgen, T., and Foregger, S. (2007). The effects of argument quality and involvement type on attitude formation and attitude change: a test of dual-process and social judgment predictions. Hum. Commun. Res. 33, 81-102. doi: 10.1111/j.1468-2958.2007.00290.x

Penke, L. (2011). "Bridging the gap between modern evolutionary psychology and the study of individual differences," in The Evolution of Personality and Individual Differences, eds D. M. Buss and P. H. Hawley (New York, NY: Oxford University Press), 243-279.

Penke, L., Borsboom, D., Johnson, W., Kievit, R. A., Ploeger, A., and Wicherts, J. M. (2011). Evolutionary psychology and intelligence research cannot be integrated the way Kanazawa (2010) suggested. Am. Psychol. 66, 916-917. doi: 10.1037/a0024626

Penke, L., Denissen, J. J. A., and Miller, G. F. (2007a). Evolution, genes, and inter-disciplinary personality research. Eur. J. Pers. 21, 639-665. doi: $10.1002 /$ per.657

Penke, L., Denissen, J. J. A., and Miller, G. F. (2007b). The evolutionary genetics of personality. Eur. J. Pers. 21, 549-587. doi: 10.1002/ per.629

Pinker, S. (1997). How the Mind Works. New York, NY: Norton.

Pinker, S. (2002). The Blank Slate: The Modern Denial of Human Nature. New York, NY: Viking.

Pinker, S., and Bloom, P. (1992). "Natural language and natural selection," in The Adapted Mind: Evolutionary Psychology and the Generation of Culture, eds J. H. Barkow, L. Cosmides, and J. Tooby (New York, NY: Oxford University Press), 451-494.

Reeve, C. L., and Charles, J. E. (2008) Survey of opinions on the primacy of $g$ and social consequences of ability testing: a comparison of expert and nonexpert views. Intelligence 36, 681-668. doi: 10.1016/j.intell.2008.03.007

Reisner, A. (2005). The common factors, empirically validated treatments, and recovery models of therapeutic change. Psychol. Rec. 55, 377-400.

Resnik, D. (1996). Adaptationism: hypothesis or heuristic? Biol. Philos. 12, 39-50. doi: 10.1023/A: 1017936706537

Richards, M. (1986). Relationships between the Eysenck Personality Questionnaire, Strelau Temperament Inventory and Freiburger Beschwerdenliste Gesamtform. Pers. Individ. Dif. 7, 587-589. doi: 10.1016/0191-8869 (86) $90139-\mathrm{X}$

Richardson, R. (2007). Evolutionary Psychology as Maladapted Psychology. Cambridge, MA: MIT Press.

Rodeheffer, C. D., Daugherty, J. R., and Brase, G. L. (2011). Resistance to evolutionary psychology as a continuation of conflicts over scientific integration. Futures 43, 777-786. doi: $\quad$ 10.1016/j.futures.2011. 05.021

Rogers, A. G. (2000). When methods matter: qualitative research issues in psychology. Harv. Educ. Rev. 70 75-85.

Rose, H., and Rose, S. (2000). Alas Poor Darwin: Arguments Against Evolutionary Psychology. New York, NY: Harmony Books.

Rosset, E. (2008). It's no accident: our bias for intentional explanations. Cognition 108, 771-780. doi: $\quad$ 10.1016/j.cognition.2008. 07.001

Rushton, J. P. (1985). Differential K theory: the sociobiology of individual and group differences. Pers. Individ. Dif. 6, 441-452. doi: 10.1016/01918869(85)90137-0

Rushton, J. P. (2000). Race, Evolution and Behavior: A Life History Perspective, 3rd Edn. Port Huron, MI: Charles Darwin Research Institute.

Rushton, J. P. (2004). Placing intelligence into an evolutionary framework, or how $g$ fits into the $r$ $\mathrm{K}$ matrix of life history traits including longevity. Intelligence 32 , 321-328. doi: 10.1016/j.intell.2004 06.003

Salmon, W. C. (1989). "Four decades of scientific explanation," in Minnesota Studies in the Philosophy of Science: Vol. XIII Scientific explanation, eds P. Kitcher and W. C. Salmon (Minneapolis, MN: University of Minnesota Press), 3-219.

Sappington, A. A. (1990). Recent psychological approaches to the free will versus determinism issue. Psychol. Bull. 108, 19-29. doi: 10.1037/0033-2909.108.1.19

Seligman, D. (2002). Good breeding. Natl. Rev. 54, 53-54.

Sheldon, K. M. (2011). Integrating behavioral-motive and experientialrequirement perspectives on psychological needs: a two process model. Psychol. Rev. 118 , 552-569. doi: 10.1037/ a0024758

Simonton, D. K. (2003). "Francis Galton's Hereditary Genius: Its place in the history and psychology of Science," in The Anatomy of Impact: What Makes the Great Works of Psychology Great, ed R. J. Sternberg (Washington, DC: American Psychological Association), 3-18. doi: 10.1037/10563-001

Skinner, B. F. (1953). Science and Behavior. New York, NY: The Free Press.

Skinner, B. F. (1966). The phylogeny and ontogeny of behavior. Science
153, 1203-1213. doi: $10.1126 / \mathrm{sci}-$ ence.153.3741.1205

Skinner, B. F. (1984). The evolution of behaviour. J. Exp. Anal. Behav. 41, 217-221. doi: 10.1901/jeab.1984. 41-217

Sober, E. (2000). Philosophy of Biology. Boulder, CO: Westview Press.

Staats, A. W. (1983). Psychology's Crisis of Disunity: Philosophy and Method for a Unified Science. New York, NY: Praeger.

Staats, A. W. (1999). Unifying psychology requires new infrastructure: theory, method, and a research agenda. Rev. Gen. Psychol. 3, 3-13. doi: 10.1037/1089-2680.3.1.3

Stam, H. J. (2004). Unifying psychology: epistemological act or disciplinary maneuver? J. Clin. Psychol. 60, 1259-1262. doi: 10.1002/jclp.20069

Stern, W. (1911). Differential Psychology in its Methodological Foundations, 2nd Edn. Leipzig: Barth.

Sternberg, R. J., and Grigorenko, E. L. (2001). Unified psychology. Am. Psychol. 56, 1069-1079. doi: 10.1037/0003066X.56.12.1069

Stevenson, D., and Goldworth, A. (2002). Ethical considerations in neuroimaging and its impact on decision-making for neonates. Brain Cogn. 50, 449-454. doi: 10.1016/S0278-2626(02)00523-7

Tashiro, M. (2004). Impacts of neuroimaging on psycho-oncology. Psychooncology 13, 486-489. doi: 10.1002/pon.817

Thiruchselvam, R., Blechert, J., Sheppes, G., Rydstrom, A., and Gross, J. J. (2011). The temporal dynamics of emotion regulation: an EEG study of distraction and reappraisal. Biol. Psychol. 87, 84-92. doi: 10.1016/j.biopsycho. 2011.02.009

Tooby, J., and Cosmides, L. (1989). Evolutionary psychology and the generation of culture, part I. Theoretical considerations. Ethol. Sociobiol. 10, 29-49. doi: 10.1016/0162-3095(89)90012-5

Tooby, J., and Cosmides, L. (1990). On the universality of human nature and the uniqueness of the individual: the role of genetics and adaptation. J. Pers. 58, 17-67. doi: 10.1111/j.14676494.1990.tb00907.x

Tooby, J., and Cosmides, L. (1992). "The psychological foundations of culture," in The Adapted Mind: Evolutionary Psychology and the Generation of Culture, eds J. H. Barkow, L. Cosmides, and J. Tooby (New York, NY: Oxford University Press), 19-136. 
Tooby, J., and Cosmides, L. (2005). "Conceptual foundations of evolutionary psychology," in The Handbook of Evolutionary Psychology, ed D. M. Buss (Hoboken, NJ: Wiley), 5-67.

Tooby, J., and Cosmides, L. (2007). Evolutionary psychology, ecological rationality, and the unification of the behavioral sciences. Comment on A framework for the unification of the behavioral sciences, by Gintis. Behav. Brain Sci. 30, 42-43. doi: 10.1017/S0140525X07000854

Tooby, J., Cosmides, L., and Barrett, H. C. (2005). "Resolving the debate on innate ideas: learnability constraints and the evolved interpenetration of motivational and conceptual functions," in The Innate Mind: Structure and Contents, eds P. Carruthers, S. Laurence, and S. Stich (New York, NY: Oxford University Press), 305-337. doi: 10.1093/acprof:oso/9780195179675. 003.0018

Tucker, J. S., Sinclair, R. R., and Thomas, J. L. (2005). The multilevel effects of occupational stressors on soldiers' well-being: organizational attachment, and readiness. J. Occup. Health Psychol. 10, 276-299. doi: 10.1037/1076-8998. 10.3.276

Tybout, A. M., and Scott, C. A. (1983). Availability of well-defined internal knowledge and the attitude formation process: information aggregation versus selfperception. J. Pers. Soc. Psychol. 44, 474-491. doi: 10.1037/0022-3514. 44.3.474

Tyler, L. E. (1965). The Psychology of Human Differences. New York, NY: Appleton Century Crofts.

Uher, J. (2008). Comparative personality research: methodological approaches. Eur. J. Pers. 22, 427-455. doi: 10.1002/per.680

van der Linden, D., Figueredo, A. J. de Leeuw, R. N. H., Scholte, R. H. J., and Engels, R. C. M. E. (2012). The general factor of personality (GFP) and parental support: testing a prediction from Life History Theory. Evol. Hum. Behav. 33, 537-546. doi: 10.1016/j. evolhumbehav.2012.01.007

Vandenbroucke, M. W. G., Scholte, H. S., van Engeland, H., Lamme, V. A. F., and Kemner, C. (2009). A new approach to the study of detail perception in Autism Spectrum Disorder (ASD): investigating visual feed forward, horizontal and feedback processing. Vision Res. 49, 1006-1016. doi: 10.1016/j.visres.2007.12.017

Vining, D. R. (1986). Social versus reproductive success: the central theoretical problem of human sociobiology. Behav. Brain Sci. 9, 167-215. doi: 10.1017/S0140525X00021968
Wascher, E., and Beste, C. (2010). Spatial representations as an emergent feature of perceptual processing: evidence from human electrophysiology. J. Psychophysiol. 24, 161-172. doi: 10.1027/0269-8803/a000007

Webster, G. D. (2007). Evolutionary theory's increasing role in personality and social psychology. Evol. Psychol. 5, 84-91.

Wilson, E. O. (1975). Sociobiology: The New Synthesis. Cambridge, MA: Harvard University Press.

Wilson, E. O. (1998). Consilience: The Unity of Knowledge. New York, NY: Alfred A. Knopf.

Woodley, M. A., Figueredo, A. J., Brown, S. D., and Ross, K. C. (2013). Four successful tests of cognitive differentiation-integration effort hypothesis. Intelligence. doi: $\quad$ 10.1016/j.intell.2013.02.002. (in press).

Yanchar, S. C., and Slife, B. D. (1997) Pursuing unity in a fragmented psychology: problems and prospects. Rev. Gen. Psychol. 1, 235-255. doi: 10.1037/1089-2680. 1.3.235

Young, A. (2006). Remembering the evolutionary Freud. Sci. Context 19, 175-189. doi: 10.1017/S0269889705000815

Zuroff, D. C., Fournier, M. A., Patall, E. A., and Leybman, M. J. (2010). Steps toward an evolutionary personality psychology: Individual differences in the social rank domain. Can. Psychol. 51, 58-66. doi: $10.1037 / \mathrm{a} 0018472$

Conflict of Interest Statement: The authors declare that the research was conducted in the absence of any commercial or financial relationships that could be construed as a potential conflict of interest.

Received: 30 July 2013; paper pending published: 22 August 2013; accepted: 03 September 2013; published online: 23 September 2013.

Citation: Marsh T and Boag S (2013) Evolutionary and differential psychology: conceptual conflicts and the path to integration. Front. Psychol. 4:655. doi: 10.3389/fpsyg.2013.00655

This article was submitted to Evolutionary Psychology and Neuroscience, a section of the journal Frontiers in Psychology.

Copyright (c) 2013 Marsh and Boag. This is an open-access article distributed under the terms of the Creative Commons Attribution License (CC BY). The use, distribution or reproduction in other forums is permitted, provided the original author(s) or licensor are credited and that the original publication in this journal is cited, in accordance with accepted academic practice. No use, distribution or reproduction is permitted which does not comply with these terms. 